\title{
O "SENTIR" DA POPULAÇÃO SOBRE A TRANSFORMAÇÃO DOS CAMPOS DO BAIXO MONDEGO*
}

\author{
A. C. Almeida ${ }^{* *}$, A. F. Soares***, J. G. Santos ${ }^{* *}$, L. Cunha ${ }^{* *}$, A. Tavares ${ }^{* * *}$
}

\begin{abstract}
RESUMO
Um inquérito feito a habitantes das principais povoações do Baixo Mondego, sobre as consequências das transformações operadas pelas recentes obras hidráulicas e agrícolas nesta área, permite concluir que a consciência dessas modificações é variável consoante a sua proximidade aos Campos, a idade, a actividade profisssional e a afectação directa ou não.

No geral, é dada mais importância aos impactes positivos das obras sobre o ambiente do que aos negativos. De igual modo, as alterações nas práticas culturais e o emparcelamento parece serem bem aceites pelas pessoas directamente afectadas. O estado actual do ambiente é considerado razoável a bom e o turismo é tido como pouco explorado mas com potencialidades, principalmente em Montemor-o-Velho.
\end{abstract}

Palavras-Chave: Baixo Mondego. Campo. Monte. Inquérito. Impactes Ambientais.

\section{RÉSUMÉ}

Une enquête faite aux habitants des principaux villes et villages du Bas Mondego, en ce qui concerne les conséquences des transformations opérées par les récents travaux hidrauliques et agricoles dans cet espace, permet d'en conclure que leur connaissance est variable en fonction de leur proximité aux Campos, leur âge, leur activité professionelle et leur affectation directe ou pas directe.

En générale, on donne plus d'importance aux impacts positifs qu'à ceux qui sont négatifs, en ce qui concerne les travaux sur l'environnement. Pareillement, les altérations des cultures et l'emparcellement semblent être bien acceptées par les personnes déjà directement en affectées. L'état actuel de l'environnement est évalué "raisonnable" à "bon" et le tourisme, avec des potentialités, surtout à Montemor-o-Velho, est encore peu exploité.

Mots-clés: Bas Mondego. "Campo". "Monte". Enquête. Impactes Environnementaux.

\begin{abstract}
From a survey made among the population of the main villages of the Lower Mondego, concerning the consequences of the recent hidraulic and agricultural transformations made in the area we concluded that the awareness of the said transformations varies according to distance from the Campos, age. occupation, and to the direct or indirect degree of exposure.

In general, more importance was given to the positive impacts than to the negative ones. The replacement of crops and the farm amalgamation seem also to be acceptable. The present environment conditions are thought to be from "fair" to "good"; tourism is thought as having potential yet to be explored, particularly in Montemor-o-Velho.
\end{abstract}

Key-words: Lower Mondego. "Campo". "Monte". Survey. Environmental Impacts.

\footnotetext{
* Este trabalho enquadra-se no âmbito do Programa Praxis XXI, projecto 2/21/CTA/156/94, intitulado "Estrutura geológica, evolução da paisagem e recursos no espaço do Baixo Mondego".

** Instituto de Estudos Geográficos da Faculdade de Letras da Universidade de Coimbra.

*** Departamento de Ciências da Terra da Faculdade de Ciências e Tecnologia da Universidade de Coimbra.
} 


\section{INTRODUÇÃO}

É já vasto o leque de autores, dos seus textos e conceitos, que de modo específico ou integrando trabalhos mais amplos, se debruçaram sobre o Baixo Mondego ${ }^{1}$.

Tal como ALMEIDA et al. (1990), seguindo uma terminologia próxima da adoptada por RIBEIRO (1987, mapa VI - Divisões Geográficas), não podemos deixar de reconhecer alguma dificuldade na definição do conceito espacial de Baixo Mondego, dado tratar-se de um "espaço onde se conjugam paisagens que vão do carso aberto no chamado Maciço de Sicó, aos campos aluvionares do Mondego, ou ao despropositado "horst" de Cantanhede, em que se articulam as unidades de paisagem do baixo vale do Mondego, da Estremadura setentrional, da terminação norte dos maciços calcários e do corredor de depressões e colinas imediatas ao Maciço Marginal".

Neste sentido, e de acordo com aqueles autores, o conceito de Baixo Mondego é entendido como a porção mais ocidental da bacia hidrográfica do Rio Mondego, aquela que, prolongando-se para jusante, se inicia nas proximidades da ponte da Portela, junto a Coimbra, onde o rio deixa o Maciço Hespérico e passa a cortar unidades da Orla Mesocenozóica Ocidental Portuguesa.

Concordamos igualmente com a dicotomia proposta por GIRÃo (1933) que distingue o Campo ou Campos do Mondego e o Monte ou Serra, sendo os primeiros um espaço que apesar de grande complexidade morfo-estrutural, corresponde à "...planície aluvial de nível de base, com história a decorrer das sucessivas acumulações impostas a partir do entalhe würmiano e muito possivelmente já em tempos holocénicos" (SOARES et al. 1989), e os segundos, os relevos marginais que encaixam a planície.

É sobre este espaço físico que incide o presente trabatho cujo objectivo principal é avaliar a percepção dos efeitos das intervenções recentes, que têm vindo a ser implementadas na bacia do Mondego, com particular importância a jusante de Coimbra, pelas populações que neles e deles vivem. Pretende-se, em suma, avaliar o novo "pulsar" dos Campos e das suas gentes 2 . Para o efeito,

\footnotetext{
${ }^{1}$ Ver a propósito A. GIRÃo (1933); A. F. MARTINS (1940); O. Ribeiro (1941 e 1987); A. F. SoAREs (1989); A. C. ALMEIDA et al. (1990); F. REBELo et al. (1990).

2 Este trabalho constitui um complemento de um outro efectuado pelos mesmos autores (CunHA et al., 1999) em que se pretendeu avaliar os impactes ambientais decorrentes das recentes intervenções no Baixo Mondego, ainda que de forma subjectiva devido à natureza da metodologia utilizada - "matrizes de interacção" segundo LEOPOLD et al. (1971).
}

elaborou-se um inquérito que, com a prestimosa colaboração dos alunos de Geografia desta Universidade, serviu de base para uma entrevista directa, feita no local, a 233 pessoas seleccionadas de forma aleatória. Previamente, elaborou-se uma versão provisória do questionário, que serviu apenas para aferir a objectividade das perguntas e, consequentemente, a validade do(s) sentido(s) das próprias respostas ou da ausência delas, quer se tratasse de simples recusa em responder, quer da manifestação de desconhecimento sobre o tema questionado.

\section{ESTRUTURA GERAL DO INQUÉRITO}

$\mathrm{O}$ inquérito passado às populações apresentava uma estrutura composta por 7 grupos de questões, o primeiro dos quais visou a obtenção de um conjunto de dados relativos aos inquiridos, por local de entrevista (quadro I), que permitiria posteriormente a caracterização da amostra, em função de:

$$
\begin{aligned}
& \text { - idade } \\
& \text { - sexo } \\
& \text { - profissão } \\
& \text { - naturalidade } \\
& \text { - residência } \\
& \text { - local de trabalho }
\end{aligned}
$$

Quadro I - Número de inquiridos por local de entrevista

\begin{tabular}{|l|c|}
\hline Local de entrevista & $\mathbf{N}^{\mathbf{0}}$ de inquiridos \\
\hline Coimbra & 30 \\
Figueira da Foz & 30 \\
Alfarelos & 22 \\
Arzila & 18 \\
Ereira & 21 \\
Lavos & 20 \\
Montemor-o-Velho & 30 \\
São João do Campo & 20 \\
Taveiro & 22 \\
Tentúgal Total & 20 \\
& 233 \\
\hline
\end{tabular}

Os restantes grupos de questões, os que estruturam o corpo do inquérito, visaram a obtenção de um conjunto de informações que permitissem concluir, por exemplo, sobre o grau de conhecimento das populações relativamente a algumas transformações concretas ao conjunto das obras, ou ainda sobre o grau de satisfação das populações relativamente aos resultados obtidos, quer individual 
quer colectivamente. Os inquiridos foram, portanto, solicitados a pronunciar-se sobre questões cuja estrutura foi a seguinte:

O grupo II, que pode subdividir-se em três sub-grupos:

1. Grau de conhecimento sobre as diferentes intervenções:

- regularização do leito e protecção contra as cheias

- construção do canal e da rede de rega

- construção de infra-estruturas viárias

- emparcelamento dos campos agrícolas

2. Reconhecimento da importância do carácter local, regional ou nacional de cada um dos grupos de intervenções referidos na questão anterior.

3. Grau de satisfação em relação aos grandes objectivos a alcançar com as intervenções:

- protecção contra as cheias

- re-estruturação agrícola dos campos

- condições de rega

- produção agrícola

- acessibilidades

- abastecimento público de água

- abastecimento de água à indústria

No grupo III pretendemos averiguar qual seria a sensibilidade das populações relativamente aos impactes decorrentes do conjunto das intervenções sobre os diferentes elementos do sistema ambiental, em função do sentido dos impactes (positivos/negativos) e do grau de intensidade (fortes/moderados/fracos). Os elementos ambientais em análise foram:

- solo

- ar

- água (quantidade e qualidade)

- vida

- paisagem

- património cultural

- Homem (actividades socio-económicas)

Quando confrontados com as questões do grupo IV os inquiridos teriam de pronunciar-se sobre o estado actual do ambiente no Baixo Mondego, com um leque de possibilidades de resposta compreendido entre as situações extremas de "muito bom" e "muito mau".

Relativamente às questões do grupo $\mathrm{V}$, pretendeu-se avaliar o balanço pessoal dos inquiridos em termos de benefício/prejuízo, relativamente a algumas das transfor- mações mais importantes, talvez mesmo as que mais expectativas criaram nas populações:

- modificação de culturas

- emparcelamento

- rede de rega

- rede de estradas

As questões do grupo VI centraram-se na avaliação pessoal dos inquiridos relativamente ao estado actual da exploração dos seguintes recursos no Baixo Mondego:

- água

- solo

- barros

- areia

- pedra

- vegetação

- fauna

- paisagem

Finalmente, nas questões do grupo VII solicitou-se aos inquiridos uma opinião sobre o modo como se desenvolve a actividade turística no Baixo Mondego em função dos seguintes aspectos:

- locais de maior interesse turístico

- caracterização do grau de intensidade da actividade turística

- aspectos que poderiam ser melhorados.

\section{CARACTERIZAÇÃO GERAL DA AMOSTRA}

A propósito da estrutura geral do inquérito, já nos havíamos referido ao número de entrevistas efectuadas (cfr. Quadro I). Procurando dar uma ideia da sua repartição espacial (Fig.1), justificamos a variação que se verifica no número de inquiridos em função da diferenciação do efectivo populacional de cada uma das localidades em questão, sem ter havido, obviamente, intenção de proporcionalidade.

A caracterização da amostra sugeriu outros tipos de análise que nos permitiram agrupar os inquiridos em função da sua naturalidade e da área de residência. No primeiro caso (Fig. 2), verifica-se que do total de inquiridos apenas $15,5 \%$ não são naturais do Baixo Mondego. Já a observação da figura 3 permite-nos destacar o claro e esperado predomínio das gentes residentes no Campo (48,9\% dos inquiridos). Por outro lado, o número de inquiridos residentes nas duas principais localidades (Coimbra e Figueira da Foz) representam apenas 30,5\% 


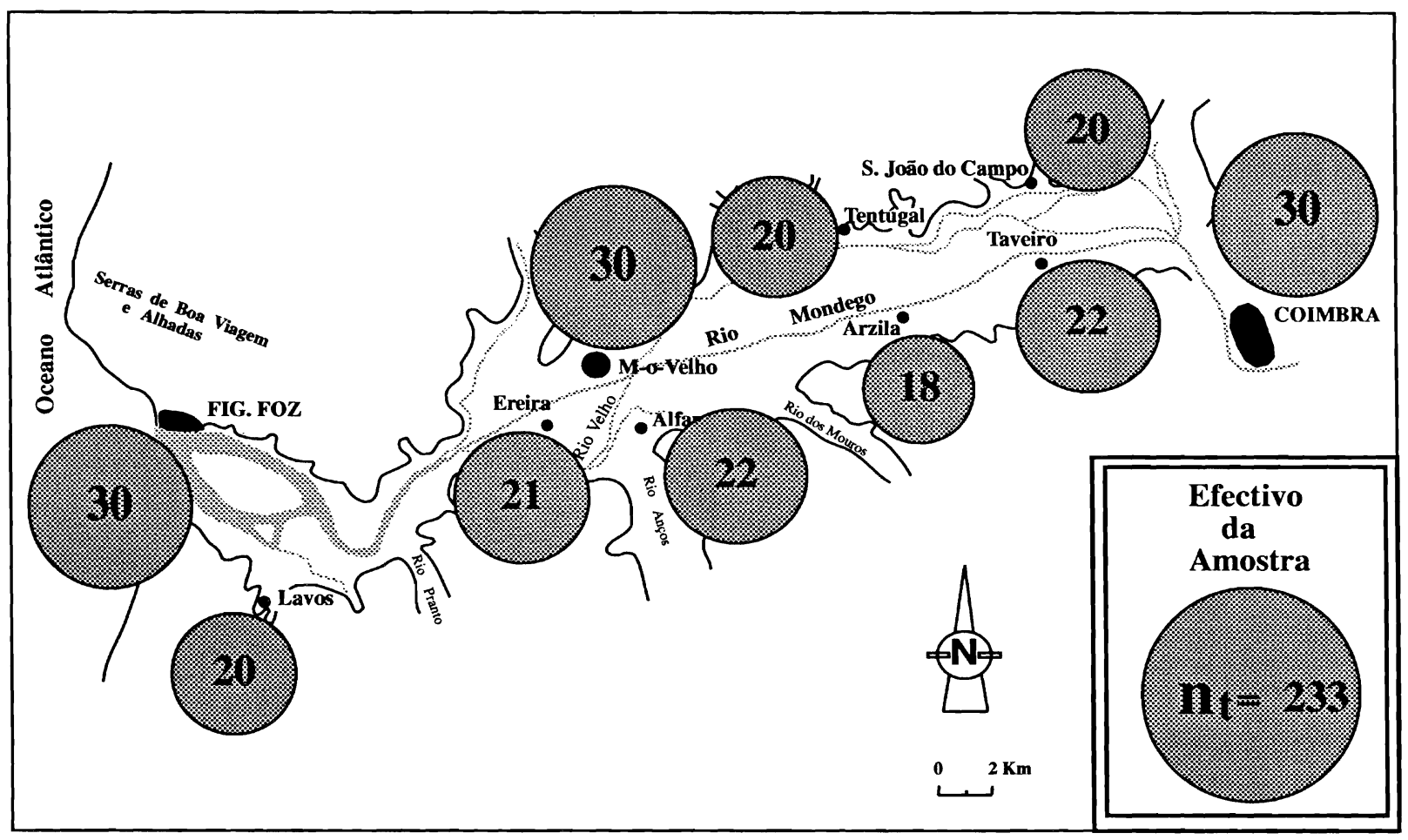

Fig. 1- Distribuição espacial da amostra

do total, enquanto apenas $3 \%$ residem fora do espaço físico do Baixo Mondego.

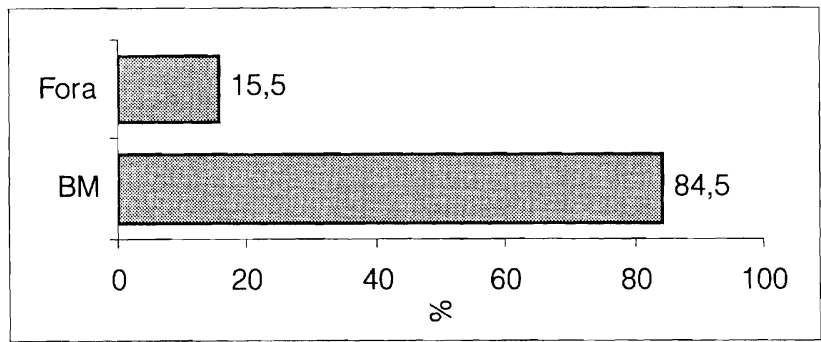

Fig. 2- Distribuição da amostra por naturalidade dos inquiridos

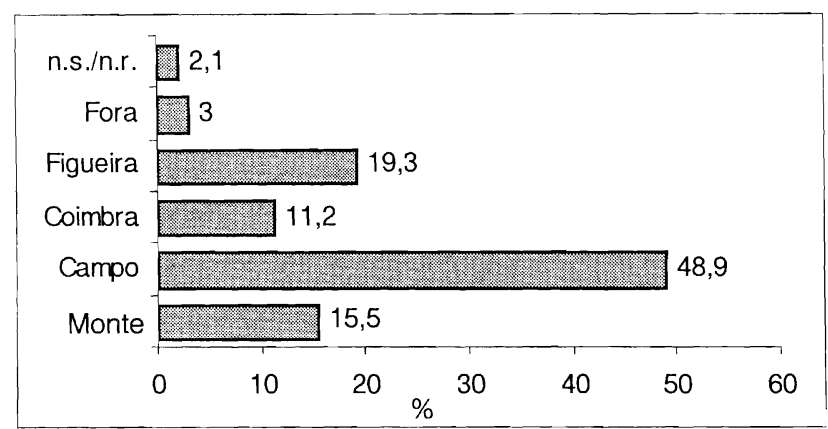

Fig. 3- Distribuição da amostra por local de residência dos inquiridos
A composição da amostra por sexo e por idade (Fig. 4) documenta a maior percentagem de inquiridos do sexo feminino com idades inferiores a 20 anos, relação que se inverte na classe dos 21-40 anos, e nas classes seguintes. No entanto, fica também a ideia geral de um relativo equilíbrio no número de inquiridos por sexos sendo a representatividade do sexo masculino (cerca de 55\%) ligeiramente maior.

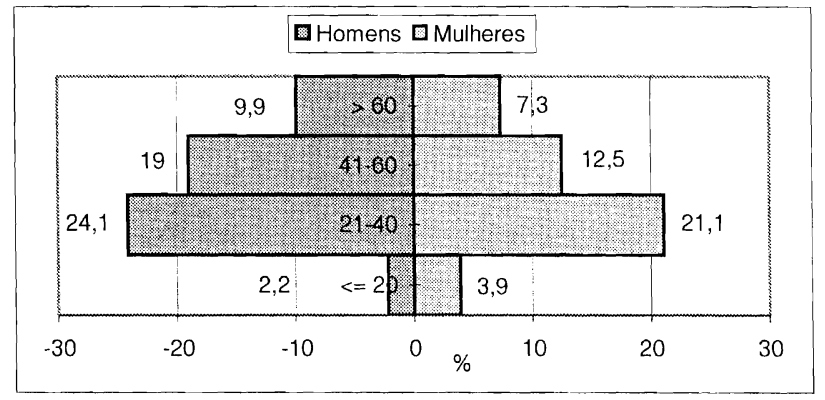

Fig. 4 - Distribuição da amostra por sexo e por idade

A concluir esta caracterização geral da amostra, o agrupamento dos inquiridos por categoria sócio-profissional (Fig. 6), permite-nos destacar os profissionais de comércio e serviços $(38,6 \%)$ e de operários $(18 \%)$. A percentagem de agricultores (4,3\%) sendo efectivamente 
reduzida, mais até do que seria desejável, não deve, no entanto ser lida isoladamente, na medida em que, por exemplo, foram vários os casos em que domésticas, reformados, operários e também os próprios profissionais

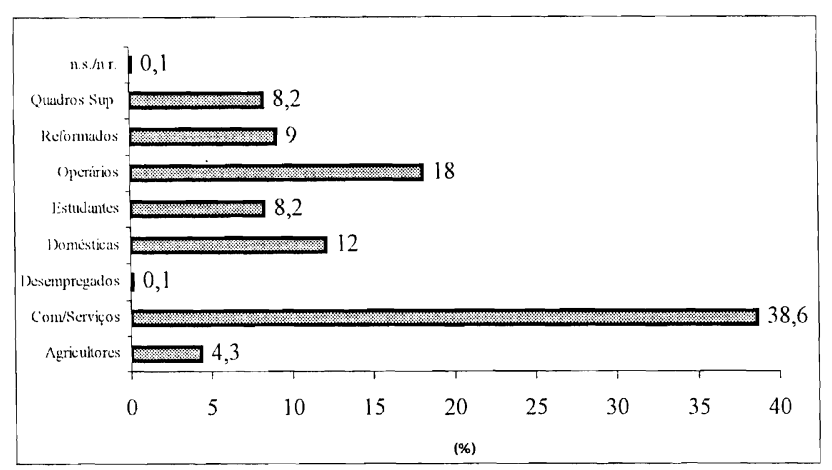

Fig. 5 - Distribuição da amostra por categoria sócio-profissional. de comércio e serviços, referiram dar à agricultura uma dedicação significativa, ainda que a tempo parcial.

\section{DADOS E RESULTADOS DO INQUÉRITO}

O conjunto das respostas obtidas legitima interpretações diversas, não necessariamente contraditórias, mas antes complementares, diferindo essencialmente em função do enfoque, da perspectiva de análise e da sensibilidade do analista. É neste quadro, que a equipa de investigadores formada por geógrafos e geólogos desenvolveu o estudo de que agora se apresentam os resultados, lidos e organizados em função da sensibilidade e do diálogo constante dos seus autores.

Começamos por manifestar alguma admiração perante o facto de a regularização do leito e protecção contra as cheias, ter tido um impacte não tão importante quanto se esperaria sobre as populações da Ereira, gente tão afectada pelas cheias no passado', pois apenas $2 / 3$ dos inqui-

Quadro II - Percentagem de inquiridos que "conhece bem" as principais intervenções efectuadas no espaço do Baixo Mondego

\begin{tabular}{|c|c|c|c|c|c|c|}
\hline & & $\mathrm{N}^{0}$ Inquiridos & $\begin{array}{l}\text { Regul. leito e } \\
\text { prot. cheias }\end{array}$ & $\begin{array}{c}\text { Canal e rede de } \\
\text { rega }\end{array}$ & $\begin{array}{c}\text { Infra-est. } \\
\text { viárias }\end{array}$ & $\begin{array}{c}\text { Emparcela- } \\
\text { mento }\end{array}$ \\
\hline & Total & 233 & 61 & 63 & 64 & 54 \\
\hline \multirow{10}{*}{ Localidade } & Alfarelos & 22 & 68 & 73 & 82 & 76 \\
\hline & Arzila & 18 & 72 & 67 & 72 & 65 \\
\hline & Coimbra & 30 & 57 & 53 & 53 & 30 \\
\hline & Ereira & 21 & 67 & 76 & 81 & 76 \\
\hline & Figueira da Foz & 30 & 43 & 40 & 47 & 33 \\
\hline & Lavos & 20 & 35 & 30 & 40 & 35 \\
\hline & Montemor & 30 & 77 & 77 & 77 & 67 \\
\hline & S. J. Campo & 20 & 85 & 85 & 80 & 84 \\
\hline & Taveiro & 22 & 59 & 77 & 64 & 45 \\
\hline & Tentúgal & 20 & 55 & 55 & 50 & 50 \\
\hline \multirow{2}{*}{ Idade } & $<40$ & $\overline{120}$ & 51 & 58 & 54 & 48 \\
\hline & $\geq 40$ & 113 & 73 & 67 & 74 & 61 \\
\hline \multirow{2}{*}{ Sexo } & Homens & 128 & 55 & 61 & 62 & 53 \\
\hline & Mulheres & 105 & 67 & 65 & 66 & 55 \\
\hline \multirow{8}{*}{$\begin{array}{l}\text { Categoria } \\
\text { sócio- } \\
\text { profissional }\end{array}$} & Agricultores & 10 & 100 & 90 & 90 & 90 \\
\hline & Comércio/serviços & 90 & 56 & 58 & 58 & 51 \\
\hline & Operários & 42 & 64 & 60 & 71 & 55 \\
\hline & Quad. Superiores & 19 & 68 & 68 & 47 & 37 \\
\hline & Desempregados & 2 & 50 & 50 & 50 & 50 \\
\hline & Domésticas & 28 & 64 & 68 & 71 & 58 \\
\hline & Estudantes & 19 & 47 & 63 & 58 & 53 \\
\hline & Reformados & 21 & 71 & 71 & 76 & 76 \\
\hline \multirow{2}{*}{ Naturalidade } & Baixo Mondego & 197 & 63 & 65 & 67 & 56 \\
\hline & Fora do B. Mondego & 36 & 53 & 50 & 47 & 42 \\
\hline \multirow{4}{*}{ Residência } & Campo & 114 & 68 & 75 & 76 & 67 \\
\hline & Monte & 36 & 72 & 64 & 64 & 61 \\
\hline & Cidades & 71 & 44 & 41 & 45 & 32 \\
\hline & Fora do B. Mondego & 7 & 71 & 71 & 57 & 43 \\
\hline
\end{tabular}

\footnotetext{
${ }^{1}$ Depois da entrega para publicação deste artigo, no Inverno de 2000/2001, face à quantidade de precipitação caída, os valores estimados para a cheia centenária, que é de $1.200 \mathrm{~m}^{3} / \mathrm{s}$ em Coimbra, foram por várias vezes ultrapassados causando pequenas inundações e estragos nos diques do Baixo Mondego, até que nos dias 26 e 27 de Janeiro de 2001 um pico de cheia
}

que atingiu $1990 \mathrm{~m}^{3} / \mathrm{s}$ em Coimbra provocou a inundação dos Campos do Mondego com destruição de diques e uma ponte e com avultados estragos para as populações dos Campos (Ribeira de Frades, Formoselha, S. João do Campo, Montemor, Ereira). Foram as primeiras inundações após a construção das obras de regularização. 
ridos referiu "conhecer bem" as intervenções efectuadas com aquele propósito. Também nos surpreendeu o facto de a mesma resposta ser dada por apenas cerca de metade dos inquiridos de Tentúgal sobre os quatro tipos de intervenções.

A melhoria das infra-estruturas viárias e o canal e rede secundária de rega são as intervenções que, de um modo geral, são melhor conhecidas pelas populações do Baixo Mondego. O emparcelamento, actualmente ainda em curso, parece ser aquele sobre o qual as pessoas mantêm um certo alheamento, em particular, e tal como se esperava, no caso das populações de Coimbra, Figueira da Foz e Lavos, em virtude do seu menor envolvimento directo com esta questão. Refira-se, ainda, que são os inquiridos com idade superior a 40 anos os que melhor conhecem as intervenções infra-estruturais efectuadas, eventualmente, por pertencerem a essa classe de idades os proprietários ou rendeiros, os principais interventores no processo. A observação do Quadro II permite ainda confirmar, também, que são os agricultores e os reformados que demonstram um melhor conhecimento do conjunto das intervenções no espaço do Baixo Mondego, em contraponto com os quadros superiores, desempregados, estudantes e empregados de comércio e serviços.

Procurando a percepção do alcance espacial dos resultados (Quadro III), verifica-se que a maioria dos inquiridos atribui ao emparcelamento um alcance essencialmente local e regional, embora os inquiridos em Coimbra e Figueira da Foz tenham considerado tratar-se também de uma estratégia com significado supra-regional, mesmo nacional. Refira-se ainda a atribuição de importância nacional à regularização do leito e protecção contra as cheias, referida pela maioria dos inquiridos, o que só se compreende se pensarmos que as pessoas inquiridas possam ter tomado em linha de conta os graves prejuízos, materiais e humanos, normalmente associados àquelas manifestações hidrológicas extremas e que são amplamente divulgados.

No que diz respeito ao grau de sucesso dos diversos objectivos das obras (Quadro IV), o amplo leque de respostas permite destacar os seguintes aspectos:

A protecção contra as cheias parece ter sido o objectivo com maior sucesso, surgindo no extremo oposto a re-estruturação agrícola dos campos e o abastecimento de água à indústria.

O maior índice de insatisfação perante o resultado das obras, entendidas no seu conjunto, parece poder atribuirse às populações de Lavos, em contraponto com as populações de Montemor-o-Velho e Taveiro, aquelas que terão, em sua opinião, beneficiado mais com as intervenções que têm vindo a desenrolar-se no palco físico do Baixo Mondego. Não surpreende, por isso, a grande aceitação de algumas dessas intervenções e o seu elevado grau de sucesso que lhes foi atribuído, como, por exemplo, no caso da rede secundária de rega e da defesa contra as cheias

Em termos etários, salienta-se a elevada percentagem de inquiridos com idades superiores a 40 anos que defendem ter havido fortes melhorias na produção agrícola, em claro contraponto com os inquiridos da faixa etária inferior.

Os agricultores parece terem eleito a re-estruturação agrícola dos campos, as melhorias das condições de rega e da produção agrícola como os objectivos melhor alcançados; já os reformados vêem na defesa contra as cheias, os melhores resultados das intervenções.

Quadro III - Importância local, regional ou nacional das principais obras (em\%)

\begin{tabular}{|l|c|c|c|c|c|c|c|c|c|c|c|c|}
\cline { 2 - 14 } \multicolumn{1}{c|}{} & \multicolumn{4}{c|}{ Nível Local } & \multicolumn{4}{c|}{ Nivel Regional } & \multicolumn{3}{c|}{ Nível Nacional } \\
\cline { 2 - 14 } \multicolumn{1}{c|}{} & $\mathrm{A}$ & $\mathrm{B}$ & $\mathrm{C}$ & $\mathrm{D}$ & $\mathrm{A}$ & $\mathrm{B}$ & $\mathrm{C}$ & $\mathrm{D}$ & $\mathrm{A}$ & $\mathrm{B}$ & $\mathrm{C}$ & $\mathrm{D}$ \\
\hline Alfarelos & 17 & 16 & 17 & 6 & 18 & 17 & 14 & 8 & 10 & 17 & 18 & 9 \\
\hline Arzila & 18 & 16 & 16 & 6 & 18 & 17 & 14 & 7 & 16 & 14 & 19 & 6 \\
\hline Coimbra & 21 & 22 & 25 & 10 & 25 & 23 & 21 & 17 & 21 & 20 & 26 & 19 \\
\hline Ereira & 13 & 12 & 18 & 12 & 13 & 13 & 19 & 11 & 13 & 13 & 19 & 9 \\
\hline Figueira da Foz & 24 & 22 & 22 & 7 & 26 & 19 & 20 & 17 & 19 & 22 & 22 & 14 \\
\hline Lavos & 17 & 15 & 18 & 3 & 17 & 14 & 16 & 6 & 16 & 14 & 16 & 6 \\
\hline Montemor-o-Velho & 16 & 20 & 13 & 16 & 19 & 18 & 14 & 15 & 13 & 15 & 21 & 11 \\
\hline S. João do Campo & 11 & 13 & 14 & 13 & 10 & 13 & 14 & 15 & 13 & 12 & 13 & 9 \\
\hline Taveiro & 18 & 18 & 19 & 10 & 17 & 17 & 17 & 10 & 14 & 12 & 17 & 9 \\
\hline Tentúgal & 14 & 12 & 16 & 11 & 17 & 12 & 13 & 10 & 14 & 10 & 14 & 8 \\
\hline
\end{tabular}

A - Regularização do leito e protecção de cheias; B - Canal e rede de rega; C - Infra-estruturas viárias; D - Emparcelamento. 
Quadro IV- Objectivos completamente alcançados (em \%)

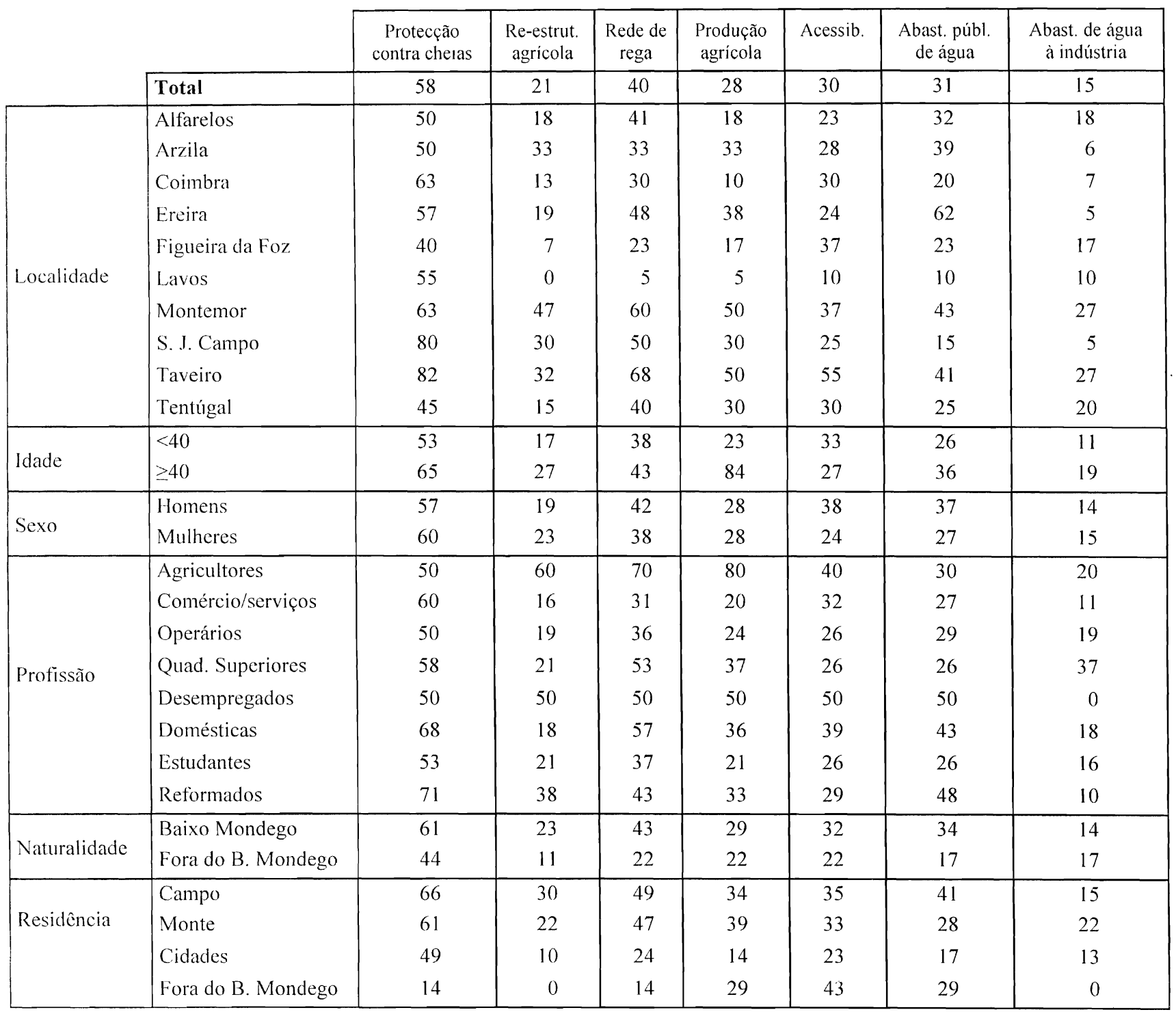

Destaque, ainda, para o facto de as gentes que residem no espaço físico do Baixo Mondego (no Monte e no Campo), bem como as que residem nos principais centros urbanos (Coimbra e Figueira da Foz) elegerem a protecção contra as cheias como objectivo melhor alcançado; já os residentes fora do Baixo Mondego apontam a acessibilidade como objectivo de maior sucesso. Ou seja, são apontadas melhorias nas actividades ou infra-estruturas mais utilizadas ou praticadas pelos inquiridos, o que abona a favor das obras.

Em matéria de impactes ambientais, as obras de regularização do leito do Rio Mondego foram passíveis de uma avaliação balizada pelos extremos "positivo forte" e "negativo forte". A análise do conjunto das respostas permite concluir que todos os elementos do ambiente terão sido afectados, embora o confronto dos quadros $\mathrm{V}$ e VI mostre que os valores extremos não assumem grande significado, com excepção dos impactes positivos sobre a quantidade de água disponível, a qualidade da paisagem e as actividades sócio-económicas.

Os autores das principais críticas negativas sobre o estado geral do ambiente no Baixo Mondego, foram os inquiridos em Tentúgal, enquanto que as populações de Arzila, Taveiro e Coimbra, parecem convencidas das significativas melhorias ambientais decorrentes das intervenções efectuadas. 
Quadro V - Impactes positivos fortes sobre o ambiente (em \%)

\begin{tabular}{|c|c|c|c|c|c|c|c|c|c|}
\hline & & Solo & $\mathrm{Ar}$ & $\begin{array}{c}\text { Quant. } \\
\text { água }\end{array}$ & $\begin{array}{l}\text { Qual. } \\
\text { água }\end{array}$ & Vida & Paisagem & $\begin{array}{l}\text { Patrim. } \\
\text { cultural }\end{array}$ & $\begin{array}{l}\text { Act. socio- } \\
\text { económicas }\end{array}$ \\
\hline & Total & 15 & 6 & 10 & 6 & 21 & 10 & 19 & \\
\hline \multirow{10}{*}{ Localidade } & Alfarelos & 3 & 5 & 18 & 5 & 0 & 18 & 0 & 5 \\
\hline & Arzila & 33 & 22 & 17 & 22 & 11 & 33 & 17 & 22 \\
\hline & Coimbra & 27 & 10 & 50 & 17 & 7 & 20 & 23 & 23 \\
\hline & Ereira & 10 & 14 & 29 & 5 & 0 & 19 & 10 & 38 \\
\hline & Figueira da Foz & 7 & 0 & 20 & 7 & 10 & 33 & 13 & 17 \\
\hline & Lavos & 0 & 0 & 5 & 5 & 5 & 15 & 5 & 15 \\
\hline & Montemor & 13 & 3 & 13 & 3 & 3 & 10 & 3 & 3 \\
\hline & S. J. Campo & 10 & 0 & 10 & 10 & 5 & 10 & 0 & 5 \\
\hline & Taveiro & 18 & 9 & 41 & 23 & 14 & 23 & 18 & 36 \\
\hline & Tentúgal & 10 & 0 & 25 & 10 & 10 & 25 & 10 & 35 \\
\hline \multirow{2}{*}{ Idade } & $<40$ & 10 & 3 & 27 & 9 & 4 & 17 & 12 & 21 \\
\hline & $\geq 40$ & 20 & 9 & 20 & 12 & 9 & 25 & 9 & 18 \\
\hline \multirow{2}{*}{ Sexo } & Homens & 13 & 5 & 21 & 9 & 3 & 23 & 7 & 19 \\
\hline & Mulheres & 17 & 7 & 26 & 12 & 9 & 19 & 13 & 20 \\
\hline \multirow{8}{*}{ Profissão } & Agricultores & 10 & 10 & 30 & 0 & 0 & 20 & 10 & 10 \\
\hline & Comércio/serviços & 17 & 4 & 28 & 10 & 6 & 21 & 9 & 20 \\
\hline & Operários & 12 & 2 & 10 & 5 & 2 & 14 & 7 & 14 \\
\hline & Quad. Superiores & 26 & 11 & 53 & 26 & 21 & 32 & 32 & 37 \\
\hline & Desempregados & 0 & 0 & 50 & 0 & 0 & 0 & 50 & 50 \\
\hline & Domésticas & 14 & 4 & 21 & 14 & 4 & 32 & 0 & 21 \\
\hline & Estudantes & 0 & 0 & 11 & 0 & 5 & 5 & 11 & 11 \\
\hline & Reformados & 24 & 24 & 19 & 19 & 14 & 24 & 14 & 19 \\
\hline \multirow{2}{*}{ Naturalidade } & Baixo Mondego & 15 & 7 & 24 & 11 & 6 & 21 & 11 & 20 \\
\hline & Fora do B. Mondego & 17 & 3 & 19 & 8 & 11 & 19 & 8 & 17 \\
\hline \multirow{4}{*}{ Residência } & Campo & 15 & 7 & 21 & 9 & 4 & 18 & 9 & 18 \\
\hline & Monte & 8 & 3 & 25 & 17 & 8 & 14 & 3 & 22 \\
\hline & Cidades & 20 & 7 & 28 & 11 & 11 & 28 & 15 & 20 \\
\hline & Fora do B. Mondego & 14 & 0 & 14 & 0 & 0 & 29 & 0 & 14 \\
\hline
\end{tabular}

Um outro tipo de análise, por idades e por sexo, permite concluir que os inquiridos com idade inferior a 40 anos denunciam um maior índice de descontentamento relativamente aos impactes sobre a vida e sobre a paisagem, enquanto esta é vista mais negativamente pelas mulheres. O solo e a quantidade de água foram os elementos do ambiente que maiores benefícios registaram, de acordo com as duas categorias de inquiridos anteriormente referidas.

Se optarmos por uma análise em termos de categorias sócio-profissionais, a qualidade do ar, que parece preocupar seriamente todos os inquiridos, sensibilizou, em particular, agricultores e desempregados. Já os quadros superiores e estudantes parecem menos receptivos aos impactes sobre a vida. Refira-se, ainda, que os profissionais de comércio/serviços (o grupo mais representativo em termos absolutos) mostraram-se relativamente pouco críticos, quer em termos positivos, quer em termos negativos. Os quadros superiores foram os inquiridos que manifestaram maior apreço pela maioria dos impactes das obras, destacando-se os que se reflectiram no aumento da quantidade de água disponível e em benefícios para as actividades sócio-económicas, estas certamente relacionadas com o aumento da produção agrícola já referida, por exemplo, em MENDES e LIMA (1996).

Finalmente, os impactes negativos fortes sobre o ar, sobre a paisagem e sobre a vida desagradam essencialmente às gentes do Campo e residentes fora do Baixo Mondego. Já a qualidade da água preocupa essencialmente os que lhe estão mais directamente sujeitos - os do Campo. 
Quadro VI - Impactes negativos fortes sobre o ambiente (em \%)

\begin{tabular}{|c|c|c|c|c|c|c|c|c|c|}
\hline & & Solo & $\mathrm{Ar}$ & $\begin{array}{c}\text { Quant. } \\
\text { água }\end{array}$ & $\begin{array}{l}\text { Qual. } \\
\text { Água }\end{array}$ & Vida & Paisagem & $\begin{array}{l}\text { Patrim. } \\
\text { cultural }\end{array}$ & $\begin{array}{l}\text { Act. socio- } \\
\text { económicas }\end{array}$ \\
\hline & Total & 3 & 12 & 1 & 6 & 9 & 8 & 6 & 2 \\
\hline \multirow{10}{*}{ Localidade } & Alfarelos & 0 & 5 & 0 & 0 & 0 & 5 & 9 & 5 \\
\hline & Arzila & 0 & 0 & 6 & 11 & 6 & 0 & 0 & 0 \\
\hline & Coimbra & 3 & 7 & 0 & 0 & 10 & 7 & 0 & 3 \\
\hline & Ereira & 5 & 24 & 0 & 14 & 0 & 5 & 0 & 0 \\
\hline & Figueira da Foz & 7 & 10 & 0 & 3 & 7 & 3 & 7 & 0 \\
\hline & Lavos & 0 & 15 & 0 & 0 & 0 & 0 & 0 & 0 \\
\hline & Montemor & 0 & 17 & 0 & 7 & 27 & 17 & 7 & 3 \\
\hline & S. J. Campo & 0 & 25 & 0 & 0 & 0 & 5 & 10 & 0 \\
\hline & Taveiro & 5 & 9 & 5 & 18 & 14 & 9 & 18 & 0 \\
\hline & Tentúgal & 15 & 15 & 5 & 15 & 25 & 25 & 15 & 5 \\
\hline \multirow{2}{*}{ Idade } & $<40$ & 3 & 9 & 1 & 8 & 14 & 13 & 7 & 3 \\
\hline & $\geq 40$ & 4 & 16 & 2 & 5 & 4 & 2 & 6 & 1 \\
\hline \multirow{2}{*}{ Sexo } & Homens & 1 & 13 & 1 & 5 & 9 & 5 & 7 & 2 \\
\hline & Mulheres & 5 & 13 & 2 & 8 & 10 & 10 & 6 & 2 \\
\hline \multirow{8}{*}{ Profissão } & Agricultores & 0 & 30 & 5 & 0 & 0 & 0 & 10 & 0 \\
\hline & Comércio/serviços & 2 & 7 & 0 & 3 & 6 & 6 & 6 & 0 \\
\hline & Operários & 5 & 12 & 0 & 14 & 12 & 14 & 12 & 5 \\
\hline & Quad. Superiores & 11 & 16 & 0 & 5 & 32 & 21 & 0 & 5 \\
\hline & Desempregados & 0 & 50 & 0 & 50 & 0 & 0 & 50 & 0 \\
\hline & Domésticas & 4 & 25 & 0 & 7 & 7 & 4 & 7 & 0 \\
\hline & Estudantes & 0 & 0 & 0 & 5 & 21 & 11 & 5 & 5 \\
\hline & Reformados & 5 & 19 & 0 & 5 & 0 & 0 & 0 & 0 \\
\hline \multirow{2}{*}{ Naturalidade } & Baixo Mondego & 4 & 13 & 2 & 7 & 11 & 9 & 7 & 2 \\
\hline & Fora do B. Mondego & 3 & 8 & 0 & 6 & 3 & 3 & 6 & 0 \\
\hline \multirow{4}{*}{ Residência } & Campo & 4 & 16 & 3 & 12 & 11 & 10 & 8 & 1 \\
\hline & Monte & 6 & 11 & 0 & 0 & 11 & 8 & 6 & 6 \\
\hline & Cidades & 3 & 7 & 0 & 1 & 6 & 3 & 4 & 1 \\
\hline & Fora do B. Mondego & 0 & 14 & 0 & 0 & 14 & 14 & 14 & 0 \\
\hline
\end{tabular}

Em função da apreciação mais pormenorizada do estado do ambiente traduzida pelas respostas à questão anterior, a quarta pergunta do inquérito surge como uma síntese natural do balanço então efectuado. Não nos surpreende, por esse facto, que os resultados apontem no sentido de um posicionamento dos inquiridos no designado meio termo (estado razoável do ambiente), uma das alternativas de resposta. Já os extremos "Bom a Muito Bom" e "Mau a Muito Mau" obtiveram um reduzido volume de respostas (Quadro VII), particularmente, na última das situações acima referidas. Em termos de espacialidade, confirmam-se os inquiridos em Tentúgal como os menos satisfeitos com o estado geral do ambiente no Baixo Mondego.

Salienta-se, também, o maior optimismo dos inquiridos com idades superiores a 40 anos.
As questões do ambiente, demonstraram como anteriormente já se disse, um grau de satisfação razoável das populações em geral, o que apenas parece não ser partilhado por uma significativa percentagem de inquiridos pertencentes à categoria sócio-profissional de operários.

Em resposta à questão $\mathrm{n}^{\circ} 5$ do inquérito, que pretendia dos inquiridos um balanço pessoal, directo ou indirecto, das obras no Baixo Mondego, os resultados, em geral francamente positivos, encontram-se sintetizados no quadro VIII.

Assim, a modificação de culturas, o emparcelamento, a rede de rega e a rede de estradas traduziram-se, de um modo geral em benefícios pessoais para a maioria das pessoas inquiridas. Destacam-se, principalmente, as melhorias na rede de estradas e na rede de rega. No 
Quadro VII - Estado actual do ambiente no Baixo Mondego (\%)

\begin{tabular}{|c|c|c|c|c|}
\hline & & $\begin{array}{l}\text { Muito } \\
\text { Bom } \\
\text { e Bom }\end{array}$ & Razoável & $\begin{array}{c}\text { Mau e } \\
\text { Muito Mau }\end{array}$ \\
\hline & Total & 26 & 68 & 6 \\
\hline \multirow{10}{*}{ Localidade } & Alfarelos & 18 & 77 & 5 \\
\hline & Arzila & 33 & 67 & 0 \\
\hline & Coimbra & 37 & 63 & 0 \\
\hline & Ereira & 33 & 62 & 5 \\
\hline & Figueira da Foz & 20 & 77 & 3 \\
\hline & Lavos & 20 & 70 & 10 \\
\hline & Montemor & 30 & 67 & 3 \\
\hline & S. J. Campo & 10 & 90 & 0 \\
\hline & Taveiro & 27 & 64 & 9 \\
\hline & Tentúgal & 25 & 50 & 25 \\
\hline \multirow{2}{*}{ Idade } & $<40$ & 21 & 72 & 7 \\
\hline & $\geq 40$ & 31 & 65 & 4 \\
\hline \multirow{2}{*}{ Sexo } & Homens & 24 & 72 & 4 \\
\hline & Mulheres & 27 & 67 & 6 \\
\hline \multirow{8}{*}{ Profissão } & Agricultores & 50 & 50 & 0 \\
\hline & Comércio/serviços & 18 & 76 & 6 \\
\hline & Operários & 29 & 54 & 17 \\
\hline & Quad. Superiores & 37 & 63 & 0 \\
\hline & Desempregados & 50 & 50 & 0 \\
\hline & Domésticas & 29 & 71 & 0 \\
\hline & Estudantes & 21 & 79 & 0 \\
\hline & Reformados & 33 & 67 & 0 \\
\hline \multirow{2}{*}{ Naturalidade } & Baixo Mondego & 26 & 68 & 6 \\
\hline & Fora do B. Mondego & 22 & 75 & 3 \\
\hline \multirow{4}{*}{ Residência } & Campo & 23 & 71 & 6 \\
\hline & Monte & 36 & 61 & 3 \\
\hline & Cidades & 28 & 66 & 6 \\
\hline & Fora do B. Mondego & 14 & 86 & 0 \\
\hline
\end{tabular}

entanto, algumas destas obras geraram nas populações sentimentos discordantes e mesmo algo contraditórios, como por exemplo, em Arzila, decerto pela polémica que se tem gerado em torno da construção da via rápida Montemor - Ameal (TADEU et al., 1995), por considerarem afectar as condições ambientais do Paul de Arzila.

No que diz respeito à modificação de culturas e ao emparcelamento, mais delicadas por interferirem com parâmetros complexos relacionados, por exemplo, com as características do sistema de propriedade dos prédios rurais, com questões de inovação tecnológica, aumento da produtividade e do rendimento, e com as inevitáveis questões (nem sempre ultrapassáveis) de "culturas e gerações", os efeitos directos destes prolongados processos de re-estruturação agrária, actualmente ainda em curso. parece terem tido já uma significativa aceitação junto das populações de Ereira, Montemor-o-Velho, S. João do Campo e Coimbra. Talvez que o contacto, há mais tempo. das populações destas freguesias com os terrenos emparcelados tenha influído na sua maior confiança neste tipo de transformação do espaço agrário.

Factor fundamental para a caracterização do estado geral do ambiente no Baixo Mondego, os recursos naturais endógenos e o estado actual da sua exploração foram tema para a sexta questão formulada. Devemos salientar o facto de esta questão ter revelado, desde logo, um forte desconhecimento dos inquiridos relativamente ao que se verifica para além dos seus territórios vividos, ou seja, as suas respostas devem ser encaradas como traduzindo um estado de coisas que caracteriza, acima de tudo, um espaço de âmbito local.

Quadro VIII - Balanço pessoal das obras em termos de benefício/prejuízo (\%)

\begin{tabular}{|l|c|c|c|c|c|c|c|c|c|c|c|c|}
\cline { 2 - 14 } \multicolumn{1}{c|}{} & \multicolumn{3}{c|}{ Mod. Cult. } & \multicolumn{3}{c|}{ Emparc. } & \multicolumn{3}{c|}{ Rede rega } & \multicolumn{2}{c|}{ Rede estr. } \\
\cline { 2 - 14 } & Ind & Ben & Prej & Ind & Ben & Prej & Ind & Ben & Prej & Ind & Ben & Prej \\
\hline Alfarelos & 70 & 30 & 0 & 65 & 30 & 5 & 55 & 45 & 0 & 35 & 65 & 0 \\
\hline Arzila & 45 & 55 & 0 & 50 & 50 & 0 & 35 & 65 & 0 & 25 & 40 & 35 \\
\hline Coimbra & 34 & 62 & 3 & 33 & 67 & 0 & 27 & 73 & 0 & 23 & 77 & 0 \\
\hline Ereira & 24 & 71 & 5 & 33 & 57 & 10 & 19 & 81 & 0 & 29 & 71 & 0 \\
\hline Figueira da Foz & 47 & 47 & 7 & 50 & 43 & 7 & 37 & 63 & 0 & 7 & 93 & 0 \\
\hline Lavos & 44 & 44 & 11 & 44 & 44 & 11 & 44 & 56 & 0 & 15 & 70 & 15 \\
\hline Montemor-o-Velho & 55 & 45 & 0 & 30 & 67 & 4 & 11 & 85 & 4 & 7 & 86 & 7 \\
\hline S. João do Campo & 16 & 68 & 16 & 11 & 89 & 0 & 5 & 84 & 11 & 0 & 100 & 0 \\
\hline Taveiro & 32 & 64 & 5 & 59 & 41 & 0 & 36 & 64 & 0 & 14 & 73 & 14 \\
\hline Tentúgal & 70 & 25 & 5 & 65 & 35 & 0 & 65 & 35 & 0 & 30 & 60 & 10 \\
\hline
\end{tabular}


Da observação do Quadro IX, rapidamente se conclui que as populações do Baixo Mondego, no geral, consideram não existir sobre-exploração dos seus recursos naturais; quando muito a areia e a fauna, sobretudo espécies cinegéticas, são vistas por cerca de um em cada sete pessoas como sobre-exploradas. São, no essencial, os agricultores aqueles que sentem mais esta pressão sobre aqueles elementos. A paisagem, pouco referida, apenas é assinalada com algum significado por $16 \%$ dos quadros superiores, mais sensíveis para esta problemática.

A actividade turística no Baixo Mondego, tema da última das questões formuladas, revela-se ainda insuficiente, pelo menos a avaliar pelos resultados das respostas obtidas. As populações de Tentúgal, Figueira da Foz, Taveiro, Lavos e Coimbra, foram particularmente críticas relativamente a esta questão (Quadro X). Em alguns casos, denunciaram mesmo a fraca intensidade dos fluxos turísticos gerados, a sua irregularidade e o reduzido número de dias em que as pessoas permanecem nas infraestruturas de apoio existentes, com excepção da época alta relativa ao designado "turismo de sol e mar". Esta ideia não pode deixar de se relacionar com o próprio facto de os inquiridos, de um modo geral, referirem as suas terras ou outras localidades mais ou menos próximas, como os locais do Baixo Mondego de maior interesse turístico denunciando, desde logo, e entre outras interpretações, uma superlativização dos valores locais. Regista-se, no entanto, talvez também pela sua maior centralidade relativamente ao espaço em estudo, que Montemor-o-Velho encabeça a lista de preferências dos inquiridos, inde-

Quadro IX - Estado actual da exploração dos recursos naturais no Baixo Mondego (\%)

\begin{tabular}{|c|c|c|c|c|c|c|c|c|c|}
\hline & & Água & Solo & Barro & Areia & Pedra & Flora & Fauna & Paisagem \\
\hline & Total & 7 & 11 & 5 & 15 & 6 & 9 & 14 & 5 \\
\hline \multirow{10}{*}{ Localidade } & Alfarelos & 14 & 5 & 5 & 18 & 5 & 5 & 9 & 0 \\
\hline & Arzila & 0 & 0 & 0 & 0 & 0 & 6 & 11 & 0 \\
\hline & Coimbra & 7 & 23 & 3 & 17 & 7 & 10 & 7 & 7 \\
\hline & Ereira & 10 & 29 & 0 & 5 & 0 & 0 & 19 & 10 \\
\hline & Figueira da Foz & 3 & 10 & 3 & 20 & 10 & 10 & 13 & 7 \\
\hline & Lavos & 0 & 0 & 0 & 30 & 0 & 10 & 20 & 10 \\
\hline & Montemor & 10 & 13 & 17 & 20 & 13 & 27 & 13 & 7 \\
\hline & S. J. Campo & 15 & 0 & 5 & 20 & 5 & 0 & 20 & 0 \\
\hline & Taveiro & 9 & 18 & 9 & 0 & 5 & 5 & 23 & 5 \\
\hline & Tentúgal & 0 & 5 & 0 & 15 & 10 & 5 & 10 & 5 \\
\hline \multirow{2}{*}{ Idade } & $<40$ & 9 & 18 & 7 & 18 & 8 & 12 & 14 & 8 \\
\hline & $\geq 40$ & 4 & 4 & 3 & 12 & 4 & 5 & 14 & 3 \\
\hline \multirow{2}{*}{ Sexo } & Homens & 5 & 14 & 7 & 17 & 6 & 10 & 13 & 6 \\
\hline & Mulheres & 9 & 9 & 3 & 13 & 6 & 8 & 15 & 5 \\
\hline \multirow{8}{*}{ Profissão } & Agricultores & 0 & 0 & 0 & 30 & 0 & 0 & 40 & 0 \\
\hline & Comércio/serviços & 9 & 13 & 6 & 17 & 8 & 9 & 14 & 7 \\
\hline & Operários & 10 & 7 & 2 & 7 & 7 & 5 & 7 & 2 \\
\hline & Quad. Superiores & 5 & 21 & 11 & 16 & 11 & 21 & 21 & 16 \\
\hline & Desempregados & 0 & 50 & 0 & 50 & 50 & 50 & 0 & 0 \\
\hline & Domésticas & 4 & 4 & 4 & 14 & 0 & 4 & 7 & 4 \\
\hline & Estudantes & 11 & 26 & 11 & 21 & 5 & 21 & 21 & 5 \\
\hline & Reformados & 0 & 0 & 0 & 10 & 0 & 0 & 14 & 0 \\
\hline \multirow{2}{*}{ Naturalidade } & Baixo Mondego & 6 & 11 & 5 & 15 & 6 & 8 & 13 & 5 \\
\hline & Fora do B. Mondego & 11 & 11 & 6 & 17 & 8 & 11 & 19 & 6 \\
\hline \multirow{4}{*}{ Residência } & Campo & 8 & 9 & 4 & 11 & 6 & 7 & 16 & 4 \\
\hline & Monte & 6 & 19 & 11 & 19 & 3 & 11 & 17 & 8 \\
\hline & Cidades & 6 & 11 & 3 & 18 & 7 & 8 & 10 & 6 \\
\hline & Fora do B. Mondego & 14 & 0 & 0 & 29 & 14 & 29 & 29 & 14 \\
\hline
\end{tabular}


Quadro X - Locais de maior interesse turístico no Baixo Mondego (em \%)

\begin{tabular}{|c|c|c|c|c|c|c|c|c|}
\hline & & Coimbra & $\begin{array}{c}\text { Montemor- } \\
\text {-o-Velho }\end{array}$ & $\begin{array}{l}\text { Figueira } \\
\text { da Foz }\end{array}$ & $\begin{array}{l}\text { Paul de } \\
\text { Arzila }\end{array}$ & $\begin{array}{c}\text { Rio } \\
\text { Mondego }\end{array}$ & $\begin{array}{c}\text { Serra da } \\
\text { Boa Viagem }\end{array}$ & $\begin{array}{l}\text { Pouca } \\
\text { Intens. }\end{array}$ \\
\hline & Total & 9 & 34 & 10 & 13 & 2 & 1 & 76 \\
\hline \multirow{10}{*}{ Localidade } & Alfarelos & 9 & 32 & 0 & 14 & 0 & 0 & 77 \\
\hline & Arzila & 0 & 6 & 0 & 89 & 0 & 0 & 50 \\
\hline & Coimbra & 27 & 23 & 7 & 13 & 0 & 0 & 83 \\
\hline & Ereira & 5 & 57 & 0 & 0 & 10 & 0 & 62 \\
\hline & Figueira da Foz & 7 & 33 & 20 & 3 & 3 & 3 & 87 \\
\hline & Lavos & 5 & 30 & 40 & 0 & 5 & 0 & 85 \\
\hline & Montemor & 10 & 63 & 10 & 0 & 0 & 0 & 57 \\
\hline & S. J. Campo & 0 & 30 & 10 & 0 & 5 & 0 & 75 \\
\hline & Taveiro & 23 & 14 & 5 & 32 & 0 & 0 & 86 \\
\hline & Tentúgal & 0 & 40 & 10 & 0 & 0 & 5 & 90 \\
\hline \multirow{2}{*}{ Idade } & $<40$ & 11 & 37 & 9 & 10 & 2 & 1 & 78 \\
\hline & $\geq 40$ & 8 & 31 & 12 & 15 & 3 & 1 & 73 \\
\hline \multirow{2}{*}{ Sexo } & Homens & 13 & 39 & 11 & 13 & 1 & 0 & 69 \\
\hline & Mulheres & 7 & 30 & 9 & 13 & 3 & 2 & 80 \\
\hline \multirow{8}{*}{ Profissão } & Agricultores & 10 & 20 & 10 & 10 & 0 & 0 & 30 \\
\hline & Comércio/serviços & 9 & 34 & 10 & 16 & 1 & 0 & 83 \\
\hline & Operários & 10 & 38 & 2 & 12 & 0 & 0 & 81 \\
\hline & Quad. Superiores & 16 & 32 & 11 & 0 & 0 & 5 & 89 \\
\hline & Desempregados & 0 & 100 & 0 & 0 & 0 & 0 & 100 \\
\hline & Domésticas & 11 & 29 & 21 & 11 & 4 & 0 & 61 \\
\hline & Estudantes & 16 & 47 & 5 & 5 & 5 & 5 & 68 \\
\hline & Reformados & 0 & 19 & 14 & 33 & 10 & 0 & 62 \\
\hline \multirow{2}{*}{ Naturalidade } & Baixo Mondego & 8 & 32 & 10 & 15 & 3 & 1 & 75 \\
\hline & Fora do B. Mondego & 19 & 42 & 14 & 6 & 0 & 0 & 78 \\
\hline \multirow{4}{*}{ Residência } & Campo & 5 & 29 & 5 & 23 & 3 & 0 & 71 \\
\hline & Monte & 11 & 56 & 8 & 3 & 0 & 0 & 64 \\
\hline & Cidades & 13 & 34 & 17 & 6 & 3 & 3 & 87 \\
\hline & Fora do B. Mondego & 29 & 29 & 29 & 0 & 0 & 0 & 71 \\
\hline
\end{tabular}

pendentemente da idade, sexo, categoria sócio-profissional, naturalidade e residência. Quando solicitados a pronunciar-se sobre o que poderia ser feito para alterar o actual estado de coisas em matéria de intensidade turística no Baixo Mondego, os inquiridos quase sempre referiram a criação de novas e melhores infra-estruturas de apoio ao turismo, hoteleiras mas também viárias.

\section{CONCLUSÃo}

Apesar de haver, ainda, uma pequena franja da população do Baixo Mondego que, estranhamente, desconhece a existência de obras que vieram, de algum modo, transformar o espaço onde residem e trabalham, há, para a restante população, uma tomada de consciência variada e que é comandada por factores de localização e de composição. A proximidade dos "Campos" desperta mais o interesse das populações para estas transformações, mas também aos agricultores, aos idosos e aos reformados. Facto preocupante, já que ficando de certo modo alheada uma boa parte da população jovem, urbana ou não relacionada com a agricultura, vem permitir questionar se teriam sido alcançados os objectivos de desenvolvimento integrado e de melhoria do nível e qualidade de vida dos habitantes, como seria de esperar de tamanho investimento financeiro, técnico e humano. 
Outra ilação que se pode tirar é a da visão demasiado local dos problemas. Estes pouco ultrapassam os interesses ou preocupações do próprio ou da comunidade onde se integra. Talvez resida aqui a causa remota de frequentes litígios existentes entre sectores de actividade com interesses e modos de actuação tão díspares como a cerealicultura nos campos e a aquicultura e pesca no estuário (RIBEIRO, 1999). Um entendimento e colaboração intersectorial é fundamental para se poderem ultrapassar constantes desconfianças mútuas e irreparáveis danos económicos.

O bom estado em que, geralmente, foi considerado o ambiente nos Campos do Mondego é, porventura, uma das razões pela qual o turismo, tido como pouco desenvolvido, é visto como uma das actividades a incentivar, em especial em Montemor-o-Velho, através de novas e melhores infra-estruturas de apoio.

\section{BIBLIOGRAFIA}

Almeida, A. C., Soares, A. F., Cunha, L. e Marques, J. F. (1990) - "Proémio ao Estudo do Baixo Mondego". Biblos, Coimbra, vol. LXVI, pp. 17-47.

CunHA, L. (1997) - "Recursos turísticos no espaço do Baixo Mondego". Actas do Seminário "O Baixo Mondego", Coimbra, pp. 85-103.

Cunha, L., Soares, A. F., Tavares, A., Almeida, A. C. e SANTOS, J. G. (1999) - "Intervenções recentes e avaliação de impactes ambientais no Baixo Mondego". Cadernos de Geografia, Coimbra, 18, pp. 39-52.

GirÃo, A. (1933) - Esbốço duma Carta Regional de Portugal. $2^{a}$ ed., Imprensa da Universidade, Coimbra.

Hespanha, P. e ReIs, J. (1988) - O desenvolvimento do Baixo Mondego. Economias Regionais e intervenção do Estado. Com. Coord. Região Centro, 356 p.

LAPA, M. L. R. e Mendes, D. A. P. (1997) - "Os recursos não metálicos da região do Baixo Mondego. I- Gesso, sal-gema e rochas carbonatadas". Actas do Seminário "O Baixo Mondego", Coimbra, pp. 61-83.
LOUREnÇo, L. (1986) - "Aproveitamento hidráulico do Vale do Mondego". Livro-Guia da excursão de 24 de Setembro de 1986, Coimbra, pp. 45-59.

Martins, A. F. (1940) - O esforço do Homem na Bacia do Mondego. Coimbra

Martins, A. F. (1984) - "Em prol dos Campos do Mondego". Cadernos de Geografia, Coimbra, 3, pp. 3-19.

Mateus, M. L. (1986) - "Transformações estruturais da agricultura na região de Coimbra. Breve nota sobre as medidas de emparcelamento no Baixo Mondego". Actas do IV Colóquio Ibérico de Geografia, Coimbra, pp. 199- 214.

Matos, M. (1986) - "Os Campos do Mondego". Livro-Guia da excursão de 24 de Setembro de 1986, Coimbra, pp. 77-86.

Mendes, H. e LimA, J. L. P. (1996) - "Impacte dos sistemas de rega e drenagem na agricultura do Baixo Mondego. Inquérito à população". Cadernos de Geografia, Coimbra, 15, pp. $75-83$.

ReBelo, F. (1986) - "Introdução geográfica". Livro-Guia da excursão de 24 de Setembro de 1986, Coimbra, pp. 17-38.

Rebelo, F.. Cunha, L. e Almeida, A. C. (1990) - "Contribuição da Geografia Física para a inventariação das potencialidades turísticas do Baixo Mondego". Cadernos de Geografia, Coimbra, 9, pp. 3-34.

RIBEIRO, J. L. S. (1999) - Uma perspectiva sobre a problemática do ordenamento territorial do estuário do Mondego. Estratégias de desenvolvimento integrado. Fac. Letras, Univ. Coimbra (Tese de Mestrado)

Soares, A. F., Almeida, A. C. e Diniz, P. (1997) - “A margem direita do Mondego e a geomorfologia da Serra da Boa Viagem". Actas do Seminário "O Baixo Mondego", Coimbra, pp. A1-A20.

Tadeu, A. J. B., Pereira, A. P. B. M., Lima, J. L. M. P. e Mateus, D. M. R. (1995) - "Ruído de tráfego rodoviário no Paul de Arzila". Cadernos de Geografia, Coimbra, 14, pp. 105-114. 